Harrison, P., Gomes, R., and Curado-Correia, N. (2013) Press forming a 0/90 cross-ply advanced thermoplastic composite using the double-dome benchmark geometry. Composites Part A: Applied Science and Manufacturing, 54 . pp. 5669. ISSN 1359-835X

Copyright (C) 2013 Elsevier Ltd.

A copy can be downloaded for personal non-commercial research or study, without prior permission or charge

Content must not be changed in any way or reproduced in any format or medium without the formal permission of the copyright holder(s)

When referring to this work, full bibliographic details must be given

http:/eprints.gla.ac.uk/84542

Deposited on: 19 August 2013

Enlighten - Research publications by members of the University of Glasgow http://eprints.gla.ac.uk 


\title{
PRESS FORMING A 0/90 CROSS-PLY ADVANCED THERMOPLASTIC COMPOSITE USING THE DOUBLE-DOME BENCHMARK GEOMETRY
}

\author{
P. Harrison ${ }^{1 *}$, R. Gomes ${ }^{2}$ and N. Correia ${ }^{2}$ \\ ${ }^{1}$ School of Engineering, James Watt Building (South), University of Glasgow, Glasgow, G12 8QQ, UK \\ ${ }^{2}$ INEGI, Composite Materials and Structures Research, Institute of Mechanical Engineering and \\ Industrial Management, Porto 4200-465, Portugal \\ *Philip.harrison@glasgow.ac.uk
}

Keywords: B. Thermomechanical, C. Finite element analysis (FEA), D. Mechanical Testing, E. Forming

\begin{abstract}
A pre-consolidated thermoplastic advanced composite cross-ply sheet comprised of two uniaxial plies orientated at $0 / 90^{\circ}$ has been thermoformed using tooling based on the double-dome bench-mark geometry. Mitigation of wrinkling was achieved using springs to apply tension to the forming sheet rather than using a friction-based blank-holder. The shear angle across the surface of the formed geometry has been measured and compared with data collected previously from experiments on woven engineering fabrics. The shear behavior of the material has been characterised as a function of rate and temperature using the picture frame shear test technique. Multi-scale modelling predictions of the material's shear behavior have been incorporated in finite element forming predictions; the latter are compared against the experimental results.
\end{abstract}

\section{Introduction}

Thermoforming of biaxial cross-ply laminates is potentially a fast and low-cost production technology for the manufacture of high quality advanced composite components. Above the matrix melt temperature, inter-ply sliding in these materials is restricted only by the limited adhesion provided by the molten matrix layer connecting the two plies. Thus, a priori, it might be assumed that the deformation modes of such a material would be less constrained than for woven or stitched fabrics. For the latter, inter-ply sliding has recently been shown to be a significant mode of deformation during the forming process [1]. 
This investigation therefore aims to answer the following questions regarding the thermoforming behavior of biaxial cross-ply laminates when formed over doubly-curved geometries:

- Do they have enough integrity to hold together?

- Does their deformation conform closely to ideal trellis shear kinematics or is inter-ply slip significant?

- Can an existing rate-dependent constitutive model [2], originally developed for 2-D viscous textile composites, provide an accurate prediction of their thermoforming behavior?

In addition to examining the thermoforming of cross-ply laminates, a further goal of this work is to explore the influence of a wrinkling-mitigation technique currently used in industry yet rarely used in experiments or modelled in the literature [3,4], namely, the use of springs, rather than a blank-holder to induce in-plane tension in the forming sheet.

The double-dome benchmark geometry [5] is a reasonably complex shape, of industrial origin, consisting of both doubly curved surfaces and also flat surfaces from which test coupons can be cut. Engineering fabrics, including shear rate-independent glass fabric at room temperature [7-9] and shear rate-dependent co-mingled fabric at high temperature $[6,10]$ have already been formed using this geometry and the accuracy of several biaxial constitutive models in simulating these experiments has been evaluated [6-12]. Sensitivity studies by Willems $[6,10,11]$ revealed that shear angle predictions are relatively insensitive to the form of the material's shear force versus shear angle curve, while tensile properties, friction and boundary conditions applied to the perimeter of the forming blank are more significant. Many of the mechanical models examined so far have provided good predictions for woven engineering fabrics formed over the double-dome geometry. An important goal of this study is to show how by changing material and boundary conditions in ways that are relevant to industrial manufacturing processes, the double dome benchmark geometry can be used to explore the influence of such changes and to evaluate the utility of current simulation techniques and models in accounting for them. 


\section{Material}

Pre-consolidated uniaxial cross-ply sheet, approximately $0.7 \mathrm{~mm}$ thick, comprised of two layers of unidirectional glass-polypropylene (PP) plies, with a 0/90 initial fibre orientation has been used. The composite consists of a PP homo-polymer matrix containing 60\% volume fraction E-glass fibres (two consolidated layers of Polystrand ThermoPro Standard 60\% 10 series, as supplied by the manufacturer, Polystrand $\left.^{\circledR}[13]\right)$.

\section{Experimental set-up for high temperature press-forming of double-dome}

The double-dome bench mark geometry has been manufactured at INEGI as a set of matched male and female steel tools (see Figure 1). The experimental set-up used here is close to that of the benchmark setup, though certain features have been changed to facilitate forming at high temperature. In particular, the blank-holder boundary conditions and the initial blank shape have been modified (see Section 3.3).

\subsection{Manufacture of Double Dome tooling}

The CAD models for the double-dome were downloaded from [5]. The models were exported from Solidworks to CAM software (PowerMILL, Delcam) and machining was performed on a 5-axis CNC machine (Fadal, VMC 4020). The tools were fitted with heating cartridges in top and bottom tools with cooling facility in just the bottom tool, though in this investigation room temperature tooling was used in all tests.
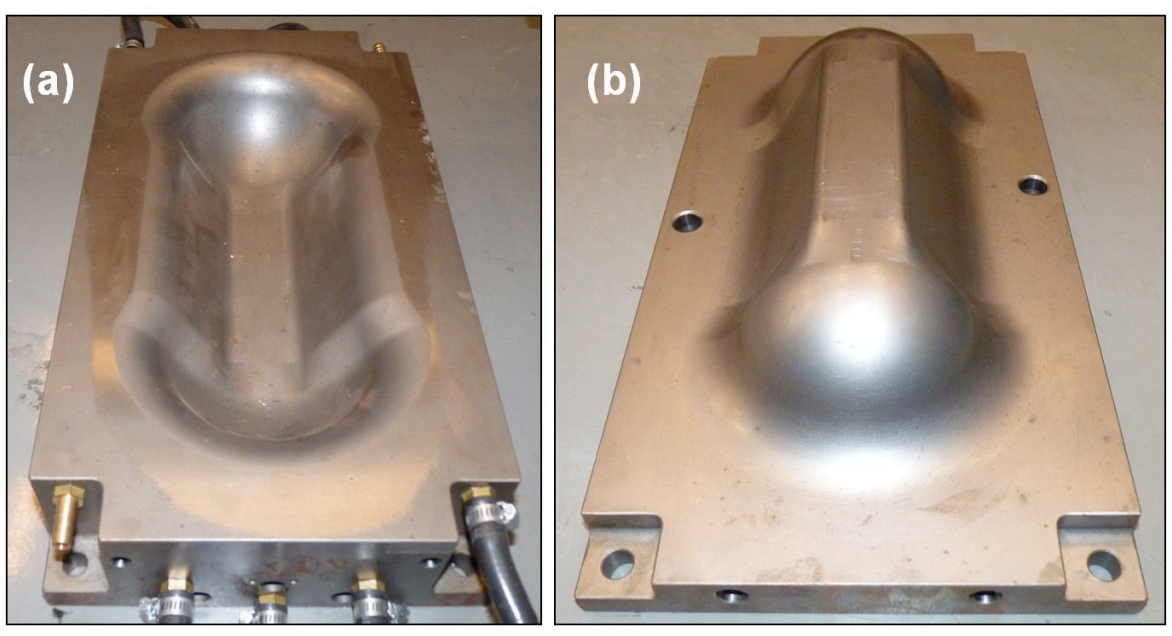

Figure 1. Tooling based on CAD model from [8]: (a) Female die, (b) Male punch. 


\subsection{Heating and transfer system}

In order to form the pre-consolidated uniaxial cross-ply sheet the polymer matrix had to be heated to above its melt-temperature and quickly transferred to the press for forming. An open-sided radiant heater oven (see Figure 2) was designed together with a compressed-air driven shuttle system, to enable fast transfer from oven to press. The heater contained eight $1 \mathrm{~kW}$ radiant heating lamps (Elstein, FSR 1000230V), situated inside the top and bottom of the oven (Figure 2a) and the blank sheet was automatically positioned between the two heaters using a blank-holder frame and shuttle rails (see Figure $2 b$ ).
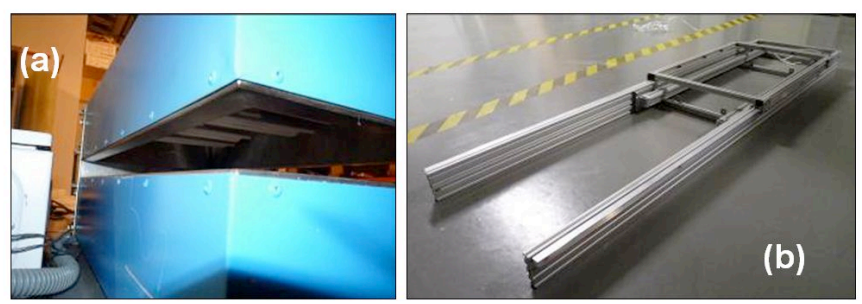

Figure 2. (a) Radiant heater used to heat blank. The upper heating lamps are visible, similar lamps are also positioned in the bottom of the oven. (b) Shuttle system frame and blank-holder frame.

After various experiments, the most controllable method of heating the sheet was found to involve preheating the oven to a set temperature with a metal partition sheet separating the top and bottom halves of the oven. Equilibrium was achieved in both regions after approximately 5 to 10 minutes. The heaters were switched off before removing the metal partition sheet and the composite blank was inserted. A $260^{\circ} \mathrm{C}$ pre-heat temperature produced the heating profile within the blank shown in Figure 3a (measured using a specially designed temperature probe involving a thermocouple sandwiched inside 2 uniaxial consolidated sheets). The blank was removed from the oven after 100s, when the rate of change of temperature of the blank was lowest (see Figure 3a). This enabled better control of the blank temperature prior to forming. The subsequent cooling rate (see Figure 3b) of the blank when removed from the oven was measured as approximately linear at $-2.96+/-0.31^{\circ} \mathrm{Cs}^{-1}$ (error indicated using standard deviation). The average shuttle transfer time was measured at $0.73+/-0.06 \mathrm{~s}$. The average press closure time was measured at $2.68 \mathrm{~s}+/-0.19 \mathrm{~s}$. Thus, the total time from removing the sheet from the oven to press closure was about $3.4+/-0.25 \mathrm{~s}$ corresponding to an approximate temperature decrease of about $10^{\circ} \mathrm{C}$. Four experiments were conducted using an oven temperature set to $260^{\circ} \mathrm{C}$, this provided an initial blank temperature of around 200 to $225^{\circ} \mathrm{C}$ before leaving the oven (see Figure 3a) and an estimated blank 
forming temperature of between 190 to $215^{\circ} \mathrm{C}$. One further experiment was conducted using an oven temperature set to $270^{\circ} \mathrm{C}$ and an estimated blank forming temperature of between 200 to $235^{\circ} \mathrm{C}$. The oven temperature and fibre orientation for these experiments is given in Cases 1 to 5 of Table 1 .
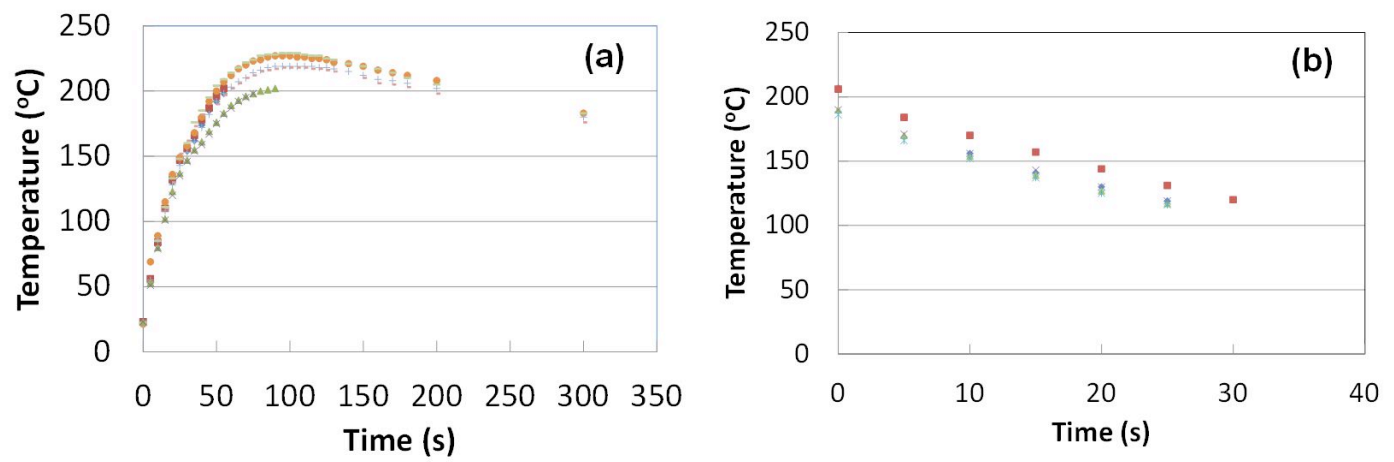

Figure 3. (a) Temperature profile of blank when placed in pre-heated oven (6 repeat tests) (b) cooling rate of blank when removed from the oven ( 5 repeat tests).

\begin{tabular}{|l|l|l|}
\hline Case Number & Oven Temperature $\left({ }^{\circ} \mathrm{C}\right)$ & Fibre orientation $\left({ }^{\circ}\right)$ \\
\hline 1 & 260 & $0 / 90$ \\
\hline 2 & 260 & $0 / 90$ \\
\hline 3 & 260 & $+/-45$ \\
\hline 4 & 270 & $+/-45$ \\
\hline 5 & 260 & $-35 /+55$ \\
\hline
\end{tabular}

Table 1. Oven temperature and initial blank orientations for the 5 formed parts.

\subsection{Blank-holder system, blank shape and spring stiffness}

The original set-up for the bench-mark experiment involves an arrangement in which the blank is constrained using a normal pressure applied to its surface using a segmented blank holder, as described in $[6,7]$. The set-up is difficult to use at high temperatures due to the need to heat the entire pre-consolidated thermoplastic blank prior to forming [6]. Also as the tribology of molten advanced composite laminates is complex, accurately modelling the friction condition within the blank-holder is not straightforward. The slip behavior involves both static and dynamic frictions both of which are rate, temperature and pressure 
dependent $[14,15]$. These practical problems and complexity of the friction condition can be avoided, at least under the blank-holder, using an alternative technique; applying tension via springs and clips, see Figure 4a. This technique is of further interest as it is currently employed in industry due to its simplicity and flexibility. Following preliminary forming trials (see, for example, Figure 4a), the blank shape had to be modified from the bench-mark prescribed geometry of 270 x $470 \mathrm{~mm}$ [e.g. 7] for two reasons: (i) During forming of the sheet, clips attached to the blank are drawn towards the tooling. If the blank is too small the clips move between the tools and are crushed as the tools close. Thus, the clips had to be a minimum distance away from the tooling at the start of the test. (ii) In order for the blank-holder frame to fit inside the oven the latter had to employ an open-sided design (see Figure 2a). Material towards the outer edges of the oven experienced a slightly lower temperature compared to that at the centre of the oven. To minimise this effect, it was preferable to decrease the size of the blank. These two constraints suggested an optimum shape for the blank involving tabs, the dimensions of which are shown in Figure 4b. By transferring the entire sheet and clips into a radiant oven for heating, only small areas of the sheet (the tabs held between the clips) remain un-melted. Springs were cut from a long section. Looped ends were made by bending the last two coils of the cut spring for attachment to bolt heads which protruded from the blank-holder frame (see inset in Figure 4a). Two different lengths were made, involving either 19 to 20 or 25 to 26 turns in the main body section. Longer springs $(20.7 \mathrm{~mm}$ body $+20 \mathrm{~mm}$ loops $)$ were used at the ends of the blank, shorter springs (15.2 mm body, $20 \mathrm{~mm}$ loops) at the side, in order to produce similar strains in the springs during forming. The stiffness and yield force of the springs were measured for each spring length, given in Table 2 together with the standard deviation of each result (from 3 tests on 3 different springs). The clip loops, to which the springs were connected, extended about $20 \mathrm{~mm}$ from the end of the clip (see inset in Figure 4a). The inner dimensions of the rectangular frame to which the springs were attached measured 452 x $640 \mathrm{~mm}$. Springs were initially orientated approximately orthogonal to the frame when attached to the sheet (see Figure 4c). An example of a final formed part is shown in Figure 4d. 

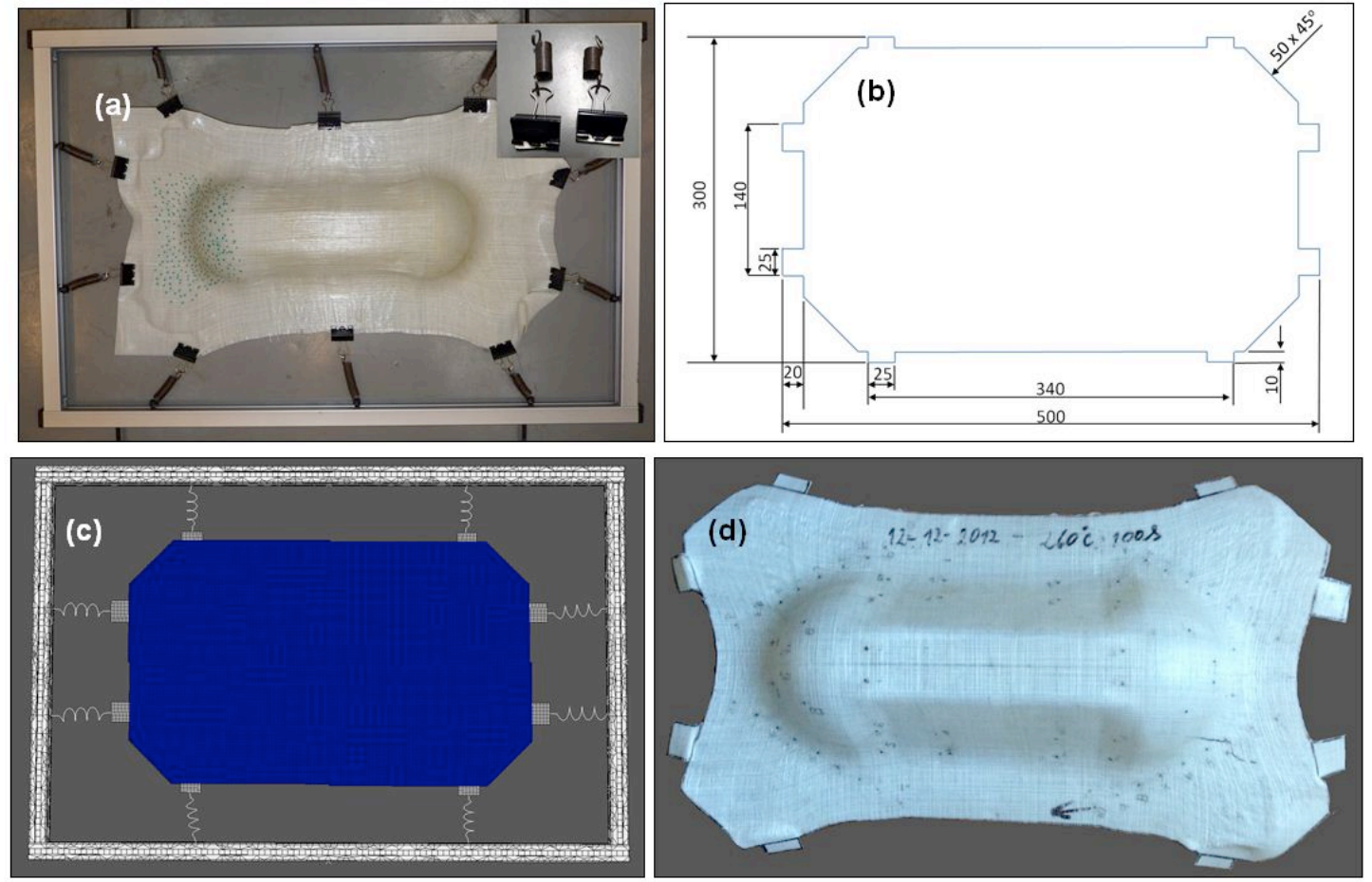

Figure 4. Formed part after preliminary tests using springs and clips to apply tension, inset shows two types of spring used to induce tension in blank during forming. Longer springs (25-26 turns) were use at the ends; shorter springs (19-20 turns) were used at the sides of the blank. Sand paper was glued inside the clips to prevent slip, (b) dimensions of optimised blank shape, (c) initial blank shape and spring locations for the final experiments and simulations, (d) example of formed 0/90 part using optimised blank shape and spring locations (Case 1, in Table 1)

\begin{tabular}{|l|l|l|l|l|}
\hline Spring & \multicolumn{2}{|l|}{ Stiffness (N/mm) } & \multicolumn{2}{l|}{ Yield load (N) } \\
\cline { 2 - 5 } & Average & S.D. & Average & S.D. \\
\hline Long & 0.201 & 0.011 & 0.935 & 0.039 \\
\hline Short & 0.266 & 0.024 & 0.709 & 0.109 \\
\hline
\end{tabular}

Table 2. Stiffness and yield load of springs (average value plus standard deviation).

\section{Shear Force Characterisation and Prediction for UD cross-ply sheet}

\subsection{Picture frame shear characterisation}

The shear response of the composite has been characterised as a function of both rate and temperature, using the picture frame test method [6]. The side length of the picture frame rig used here is $170 \mathrm{~mm}$ (clamping length $=130 \mathrm{~mm}$ ). In order to filter spurious results due to misalignment $[16,17]$ (UD 
laminates are far more sensitive to misalignment than woven fabrics due to the straightness of the fibres), a pragmatic strategy based on the following guidelines was used: (i) the result should be the lowest force curve produced under a given experimental state (rate, temperature), (ii) the result can only be used up until wrinkling of the specimen is observed during the test and (iii) the data should be physically consistent; the force versus shear angle curves should generally increase with increasing shear rate (at a given temperature) and with decreasing temperature (at a given shear rate). This technique was used in producing the data shown in Figure 5 which, for clarity, is presented using both (a) linear-linear and (b) log-linear axis.
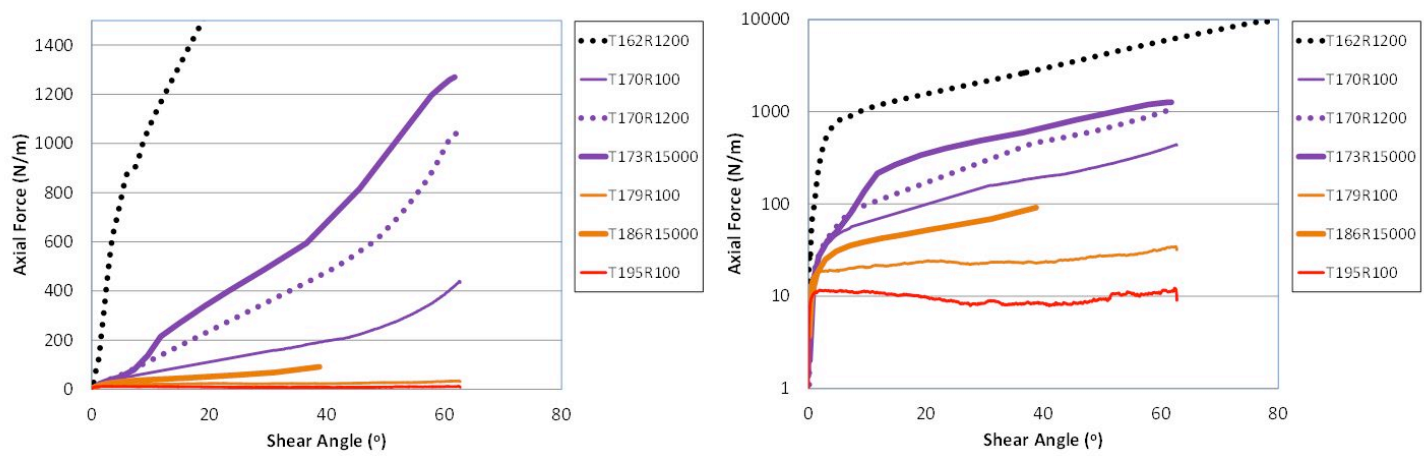

Figure 5. Normalised axial force versus shear angle results produced at various temperatures and cross-head displacement rates. For clarity, the same data are presented on (a) linear-linear and (b) log-linear axis.

A firmly clamped specimen boundary condition was used for all tests. Due to unavoidable misalignments, of the 35 tests that were conducted, only 7 were found to meet conditions (i) to (iii). The legend indicates the measured temperature in ${ }^{\circ} \mathrm{C}$ (thermocouple attached to the sample), and the crosshead displacement rate in $\mathrm{mm} / \mathrm{min}$, e.g. T162R1200 indicates a temperature of $162^{\circ} \mathrm{C}$ and a rate of $1200 \mathrm{~mm} / \mathrm{min}$. The shear angle was determined from the cross-head displacement. Friction in the picture frame rig was characterised and subtracted from the measured data (friction was a significant source of noise at the higher temperatures due to the low signal from the material). Given the high discard rate of test data, a strategy to produce enough data with which to calibrate and evaluate shear force versus shear angle predictions (see Section 4.3) using a multi-scale energy model developed previously [18] has been adopted. Ideally a greater number of picture frame tests would have been performed and these would preferably have been complemented with uniaxial bias extension data [e.g. 19, 20]. This would have improved reliability of the final dataset. Unfortunately, limitations on the amount of available material imposed practical restrictions on the number of tests that could be conducted. Picture frame tests were 
chosen over bias extension tests for this limited investigation due to concerns regarding the integrity of the composite in bias extension tests at high temperatures.

\subsection{Meso-scale kinematics during shear}

The meso-scale kinematics occurring during shear of advanced composites is a significant factor in determining the shear resistance of the material [18-24] and can influence the development of defects during forming. Two tests were conducted at both $160^{\circ} \mathrm{C}$ and $190^{\circ} \mathrm{C}$, at a cross-head displacement rate of $100 \mathrm{~mm} / \mathrm{min}$. By marking ink lines across the surface of the samples prior to testing, both along and orthogonal to the fibre direction, the material shear angle and the shear strain profile across the samples could be analysed. ImageJ [25] was used to perform image analysis using digital photographs taken at different instances in time during the course of the tests, see for example Figure 6 . The results of the analysis are shown in Figure 7 and 8. Similar observations of discontinuous meso-scale kinematics have been made previously on woven glass/molten polypropylene textile composite [18, 24], stitched noncrimp fabrics [21], engineering fabrics [23] and uniaxial prepregs [20]. In all these investigations, a discontinuous shear strain profile was observed with individual tows shearing at a lower shear strain rate than the average shear strain rate imposed across the deforming sheet. Similar shear kinematics have been observed during these tests, see Figure 6, though here the degree of discontinuity in the shear strain profile across the sheet has been found to depend strongly on temperature. 


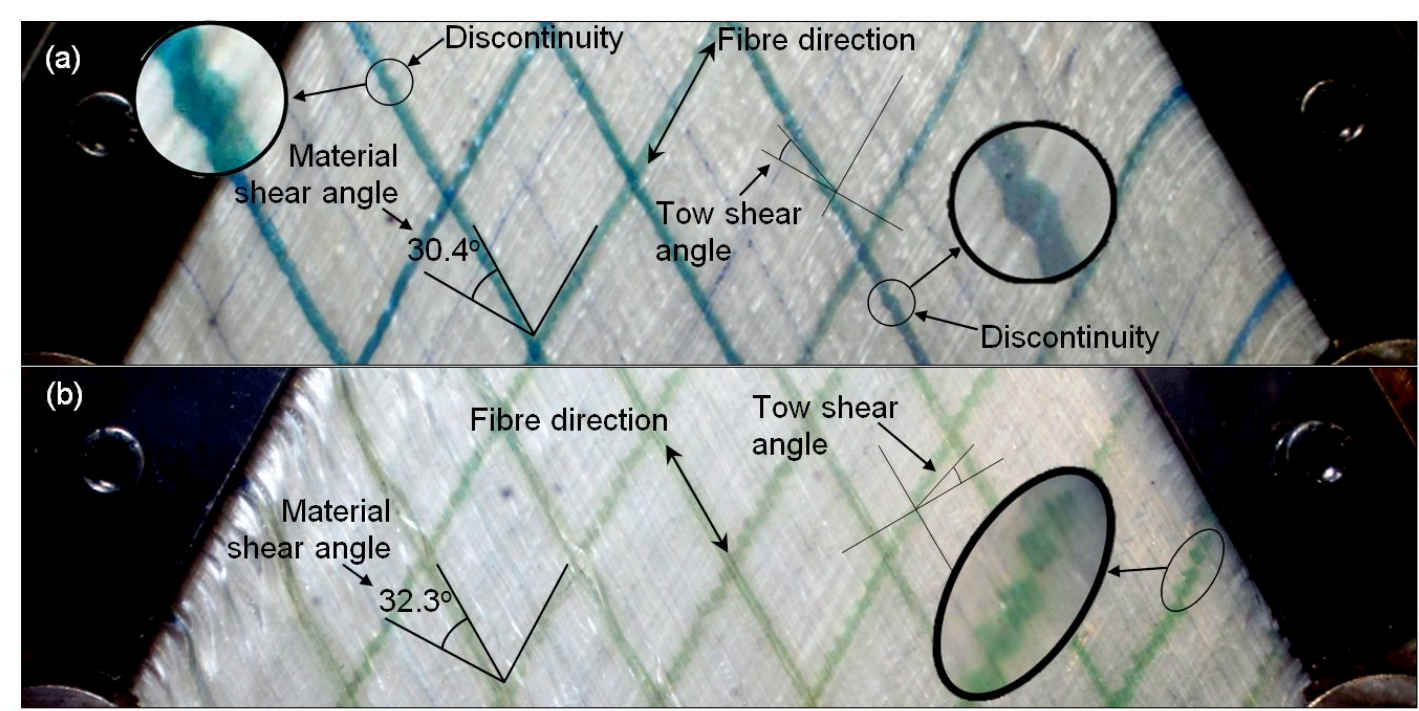

Figure 6. Shear strain profile across the surface of the sheared uniaxial cross-ply laminate at: (a) $165^{\circ} \mathrm{C}$ and (b) $190^{\circ} \mathrm{C}$. The shear strain profile is mostly continuous at the lower temperature, as seen in (a) where just a few discontinuous regions can be seen (circled in figure). In contrast, the shear strain profile is mostly discontinuous at the higher temperature, as seen in (b). Note, the ink lines are slightly faded and discoloured in (b) due to the high temperature.

Image analysis of the series of images reveals very different meso-scale kinematics occurring at the two different temperatures. At the lower temperature, only 10 to $30 \%$ of the tows were found to shear at lower shear strain rates than the average material shear strain rate. The percentage was found to depend on the shear angle (see Figure 7a), the rest of the tows sheared at approximately the same shear strain rate as the average material shear strain rate (more like a continuous sheet). Figure $7 \mathrm{~b}$ shows the tow shear angle versus the material shear angle when only the discontinuous regions are considered. Figure 8a shows the average tow shear angle versus the material shear angle when all the tows in the specimen are considered (i.e. a weighted average between the tows which shear at lower strain rates and those that shear at the average shear strain rate of the material). The average width of the tow regions was $2.21+/-0.63 \mathrm{~mm}$ and was independent of material shear angle (when divided by the cosine of the material shear angle in order to account for the lateral compressive strain). 

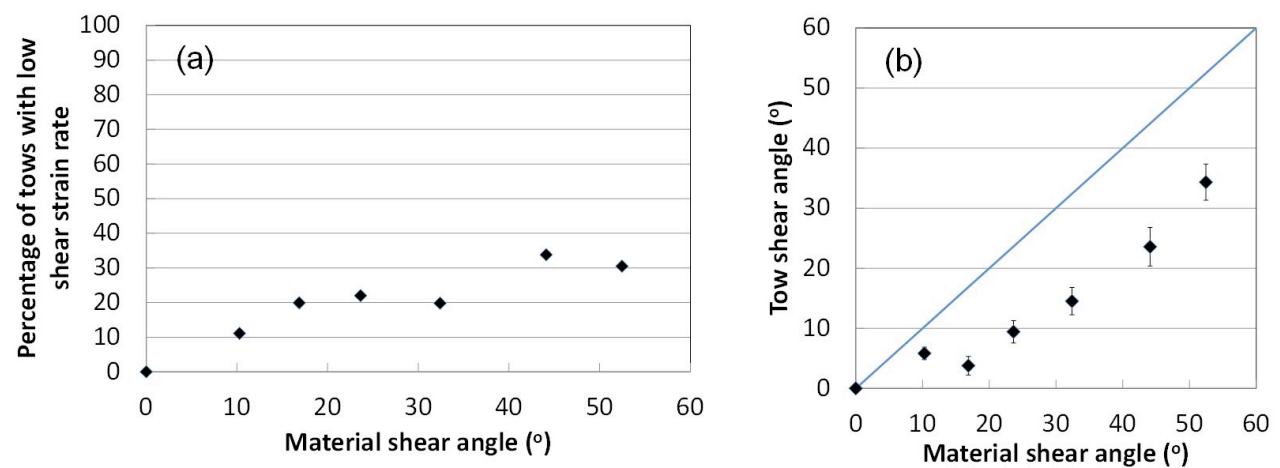

Figure 7. Meso-scale kinematics occurring at $165^{\circ} \mathrm{C}$ (a) percentage of the total number of tows showing a lower shear strain rate than the average shear strain rate of the specimen as imposed by the picture frame test (b) the tow shear angle versus the materials shear angle for just the discontinuous tows, the blue line indicates the kinematics corresponding to a continuous strain profile across the specimen
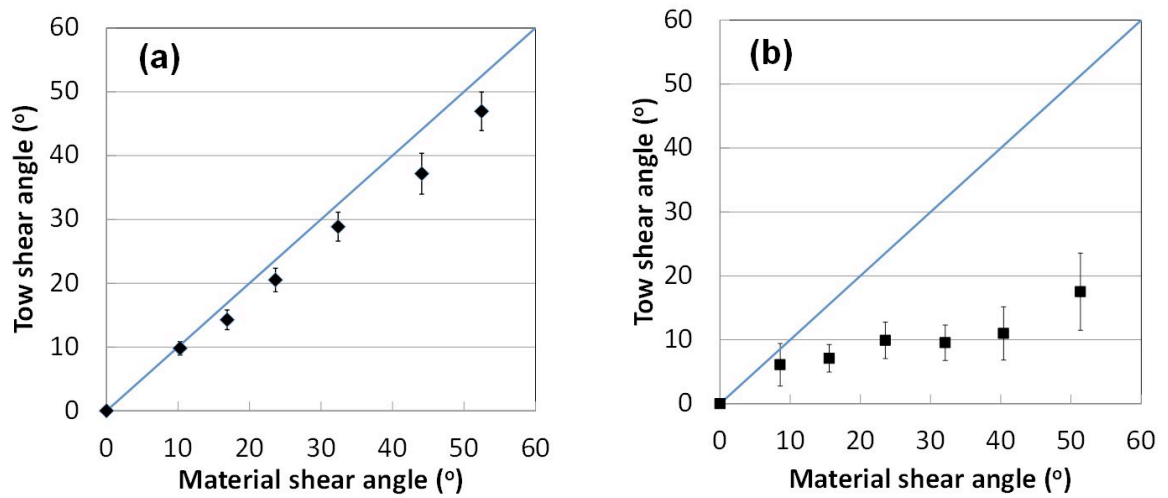

Figure 8. Average meso-scale tow shear kinematics occurring at (a) $165^{\circ} \mathrm{C}$ and (b) $190^{\circ} \mathrm{C}$. The blue line indicates the kinematics corresponding to a continuous strain profile across the specimen

In contrast, at higher temperatures almost all of the tows in the specimen sheared at lower shear strain rates than the average material shear strain rate. The average width of the tow regions was $2.10+/-$ $0.41 \mathrm{~mm}$, similar to the lower temperature. Presumably this length reflects the width of the tows from which the unidirectional sheets were made. It has been shown previously that discontinuous meso-scale kinematics have implications not only for multi-scale model predictions of the sheet's shear resistance, but also for defects occurring across the sheet during thermoforming [24].

\subsection{Multi-scale energy model shear force predictions}

Shear force versus shear angle input curves across a range of shear rates are required by the ratedependent Stress Power Model (SPM) used to simulate viscous behavior during the forming simulations [2]. To provide this data a multi-scale energy model designed to predict the shear response of pre- 
impregnated (viscous) advanced composites from fabric architecture, fibre volume fraction and matrix rheology is employed. The multi-scale energy model involves first predicting the uniaxial and transverse viscosities of a unidirectional continuous fibre reinforced fluid using two simple micromechanical models. These two viscosities can be predicted from the fibre volume fraction and rheology of the molten matrix inside the composite. Each individual tow is considered to behave as a unidirectional ideal fibre reinforced fluid. The deformation kinematics both within and between the tows can be determined if the in-plane shear kinematics of the tows are known (these currently have to be measured in shear tests). Using the two viscosity models, the ideal fibre reinforced fluid theory and the measured average tow shear kinematics, the rate of power dissipation both inside the tows and also in the region separating the tows in the horizontal plane, also known as inter-tow regions, can be determined. Fabric architecture can be taken into account by modifying the estimate of the volume occupied by the inter-tow regions using a so-called 'weave factor'. If the tows do not shear at the same angular velocity as the composite sheet, the in-plane shear stresses in the tows are reduced but an additional contribution to the viscous power dissipation arises due to so-called 'cross-over shear friction', this is approximated using an analytical equation implemented in a simple numerical algorithm. The reader is referred to [18] for a more detailed account of the multi-scale energy model used in this work. Tow kinematics measured at the higher temperature in this investigation have been quantified, see Eq. (1) \& (2), and incorporated in the model. Parameters reflecting the fabric architecture have also been adjusted to suit a uniaxial cross-ply fabric (the weave factor $q$ is set to $1[18])$.

$\chi_{t}=0.000422 \theta^{3}-0.0332 \theta^{2}+0.9311 \theta-0.0072$

$\dot{\chi}_{t} / \dot{\theta}=0.00127 \theta^{2}-0.0664 \theta+0.9311$

where $\chi_{t}, \dot{\chi}_{t}, \theta$ and $\dot{\theta}$ are the tow shear angle, the tow angular velocity, the material shear angle and the material angular velocity respectively. The specific matrix rheology of the PP matrix in the composite used in this investigation is unavailable and so the Carreau-Yasuda rheological model and Arrenhius parameters fitted to a PP characterised previously [18] have been used. The viscosity of different batches of PP can vary by several times at different rates and temperatures in a non-linear manner due to differences in molecular weight. Thus, the multi-scale energy model predictions have been multiplied by a constant scale factor at a given temperature to give an approximate match with shear force results from 
the picture frame test (black lines in Figure 9). The first reference result for the scaling has been chosen to be the T170R100 curve (see Figures 5 and 9) and a scale factor of 4.5 has been used to modify the multiscale model predictions. Axial force predictions produced by finite element picture frame simulations using the SPM incorporating the scaled multi-scale energy model predictions for both the reference test and the T170R1200 test are compared in Figure 9 (dashed grey lines). Predictions for a third cross-head displacement rate (T170R2600) are also included as these rates are close to those experienced by the composite during the forming experiments (estimated from finite element forming simulations and the average press forming time). A similar process was used to make predictions at $200^{\circ} \mathrm{C}$ at the same rates (see legend in Figure 9 - continuous grey lines), this time using the T195R100 test result as a guide (dotted black line). A constant scale factor of 0.05 was found to provide a reasonable match at this temperature. The scaled multi-scale model predictions for $200^{\circ} \mathrm{C}$ are used in the forming simulations reported in Section 3.

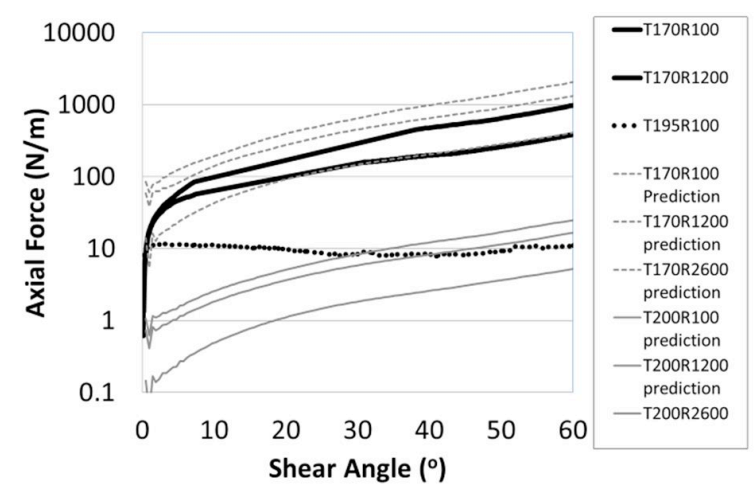

Figure 9. Multi-scale energy model predictions scaled to give a reasonable correspondence with experimental data.

\section{Experimental Thermoforming Results}

Results of thermoforming Cases 1 to 5, given in Table 1, are presented in this section. Shear angle data are presented in Section 5.1 while the deformation modes occurring during forming are described in Section 5.2. 


\subsection{Shear angle characterisation}

In order to quantify each case, shear angle measurements were recorded from 20 positions in each quadrant of each formed parts (i.e. 80 measurements for each part). To avoid ambiguity when measuring small angles [6], the acute angle facing towards either the outer edge or the nearest corner of the part was used to determine the shear angle for all measurements. Positions 1 to 10 correspond to positions 1 to 10 , as given in the benchmarking exercise [5] while positions 11 to 20 in this paper correspond to positions 1 to 10 in Khan et al. [7] (estimated from the Figures 11 and 14 of that paper. Note that positions 1 to 10 in [10] depend on the initial blank orientation, i.e. $0 / 90^{\circ}$ or $+/-45^{\circ}$ ). Example positions of points marked on the parts are shown in Figure 10 and the $(x, y)$ coordinates are given in Appendix A.
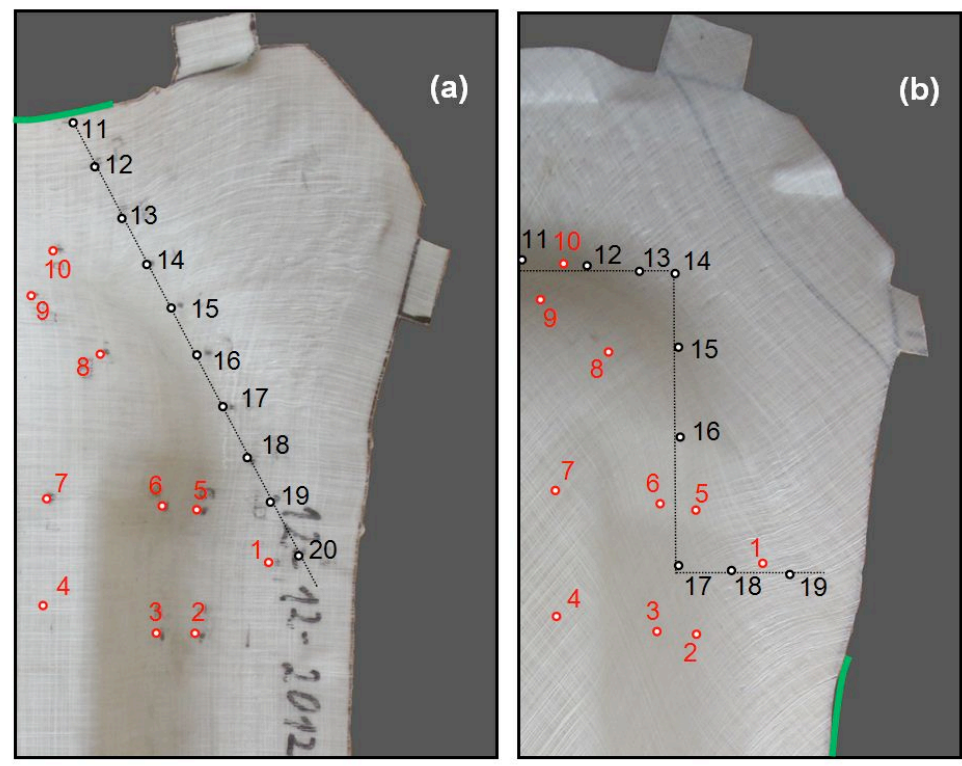

Figure 10. Approximate shear angle measurement points on each quadrant of the surface of the formed parts, the red points are those recommended in [5], the black points are those used by [7]; (a) $0 / 90^{\circ}$ initial blank orientation (b) $+/-45^{\circ}$ initial blank orientation. The green lines in the figure indicate the perimeter sections shown in detail in

Figure 12. Slight differences in the red positions are partly due to different perspectives in the photographs.

Measurements were recorded by photographing each point from an orthogonal direction and using ImageJ [25] to measure the shear angle at each of the points. Measured shear angle data are shown in Figure 11a-c and given in a tabulated form in Appendix A. For Cases 1 to 4 (see Table 1), the data points are an average of 4 measurements, one from each quarter and the full error bar (top to bottom) indicates the standard deviation in these measurements. For Case 5, the $35 / 55^{\circ}$ asymmetric orientation of the blank meant that only two points could be used to determine the average angle and standard deviation (averaged 
across the diagonally opposite quadrants). Variation in the measured shear angles is caused by several factors: (i) actual variability across the formed part, (ii) errors in correctly determining the true position for the measurement; locating an $x-y$ co-ordinate on a complex 3-D surface is not an easy task without an accurate 3-D metrological device, (iii) errors in estimating the measurement co-ordinates from Figures 10 and 13 of [7], (iv) errors in the image analysis process. Data from [7] are also plotted in Figure 11 for comparison.

Figure 11a shows the results of Cases 1 and $2\left(0 / 90^{\circ}\right)$ which are repeats of the same experiment. The error bars of all points overlap, demonstrating good repeatability of the experiments despite the variability in results. Experimental data points from [7] are also plotted and show a divergence in the measured shear angle with those of this investigation at points $13-15$ by as much as $10^{\circ}$. The reason for including this data is to highlight the difference in shear angles that can occur when forming and draping different types of advanced composites or their fabric preforms using different and industrially relevant boundary conditions. Such differences are difficult to predict using kinematic mapping algorithms but can potentially be predicted using a mechanical simulation approach, provided sufficiently accurate material and friction model are developed. Figure $11 \mathrm{~b}$ shows the results of Cases 3 and $4\left(+/-45^{\circ}\right)$ which are almost repeats; the temperature in Case 4 was $10^{\circ} \mathrm{C}$ higher than that in Case 3 . The result is a slightly different shear angle distribution across the two parts with no overlap in error bars at points $2,4,7,8$ and 18. Again shear angles measured experimentally by Khan et al. [7] are also plotted in Figure $11 \mathrm{~b}$ and again show a significant difference in the shear angle distribution, particularly at point 17 with a difference at this point greater than $15^{\circ}$. Figure $11 \mathrm{c}$ shows results of Case $5\left(35 / 55^{\circ}\right)$. As expected, the two pairs of quadrants (a,c \& b,d) shows very different shear angle results due to the asymmetric cutting of the blank. 

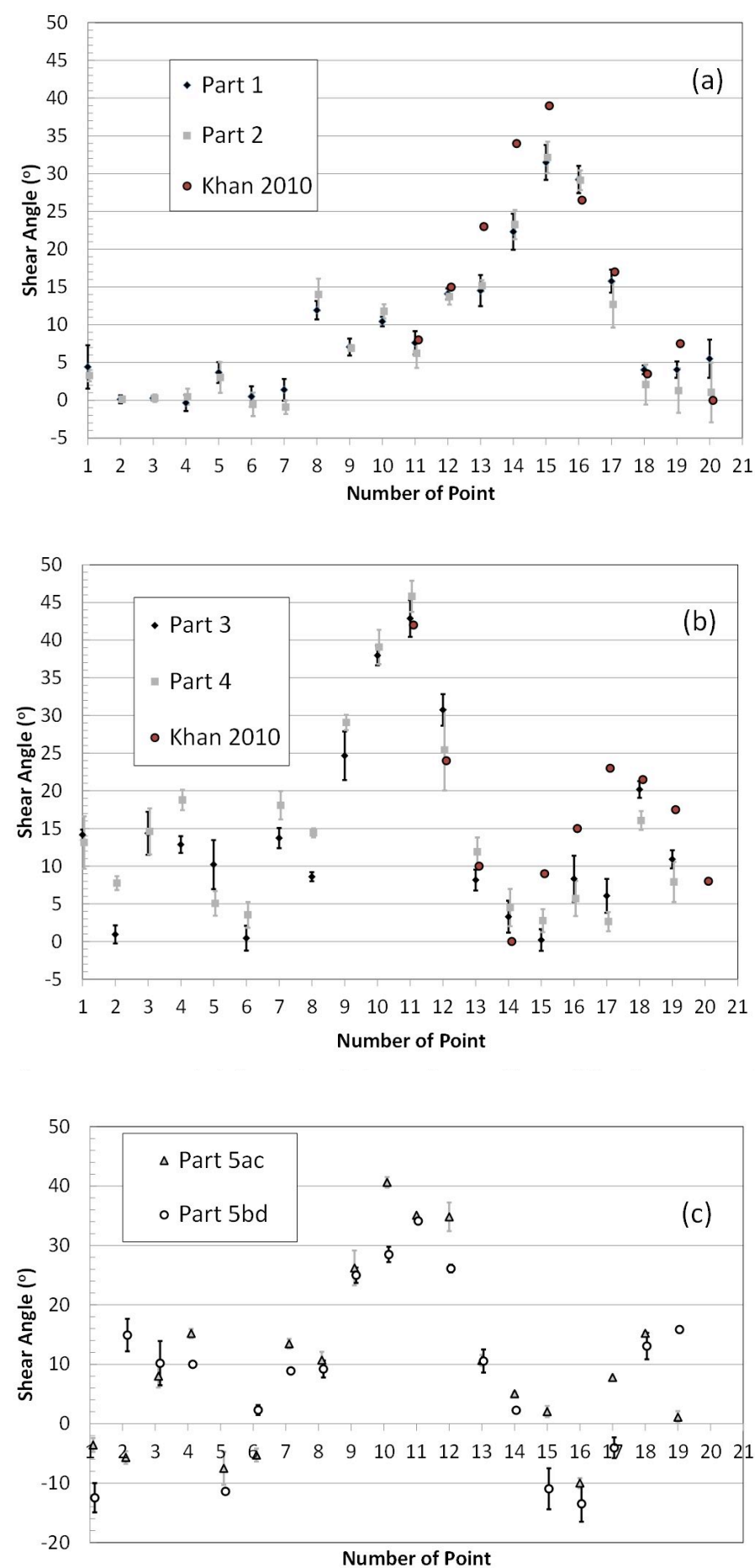

Figure 11. Shear angle measurements taken at points on the surface of the formed parts (see Figure 10). (a) Cases 1 and 2 plus data from [7] (b) Cases 3 and 4 plus data from [7] (c) Case 5 with data averaged from diagonally opposing quadrants. 


\subsection{Inter-ply slip}

An important goal of this study is to determine whether inter-ply slip is an important deformation mechanism for molten thermoplastic cross-ply laminates during thermoforming. Bel et al. [1] recently quantified inter-ply slip during the forming of stitched NCFs by examining the differences in draw-in of the two layers within the NCF along the perimeter of the formed sheet. Results showed that significant inter-ply sliding occurred, an observation that influenced the subsequent modelling approach used in their finite element forming simulations. Perhaps surprisingly, observations on the formed parts of this investigation reveal no such inter-ply sliding, see for example, Figure 12. (It should be noted that 'crossover friction', which results from the discontinuous meso-scale kinematics reported in Section 4.2, is considered here to be a separate and distinct deformation mechanism to the more severe 'interply slip' discussed by Bel et al [1], though technically speaking it could also be considered to be an inter-ply slip mechanism occurring between two adjacent plies). This suggests that for forming operations over reasonably complex doubly-curved geometries, trellis shear is the dominant deformation mechanism for molten thermoplastic biaxial cross-ply laminates and inter-ply sliding is negligible. The adhesion afforded by the molten matrix connecting the two UD layers appears to constrain their motion much more effectively than the stitching in NCFs. This observation suggests that constitutive models originally designed for woven biaxial advanced composites which assume the sheet deforms predominantly through trellis shearing are also appropriate for biaxial molten thermoplastic cross-ply laminates under reasonably complex forming conditions.

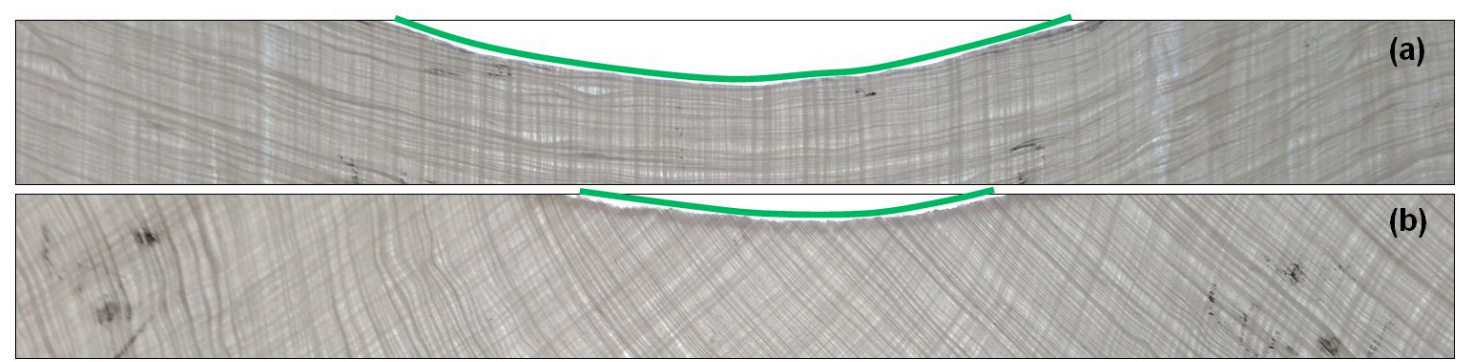

Figure 12. Sections along the perimeter of the formed parts indicated by the green line (see also Figure 10): (a) along the top edge of Case $1\left(0 / 90^{\circ}\right)$, (b) along the side edge of Case $4\left(+/-45^{\circ}\right)$. There is no evidence of inter-ply slip between the two unidirectional layers. 


\section{Comparison of Experiments and Simulations}

In this paper only the $0-90^{\circ}$ fibre orientation sheet is simulated, future work will involve analyzing all fibre orientations used in the experiments and aim to provide an in-depth sensitivity study of both material parameters and boundary conditions. The main goal here is simply to demonstrate the use of a predictive modelling approach in analysing the experiments. The finite element model used in this investigation consists of mutually constrained (sharing the same nodes) linear membrane (type S4R) and truss elements (type T3D2), similar to the approach described in [4]. Truss elements are used to represent the fibre reinforcement while membrane elements are used to represent the shear stress in the sheet and to model contact with the tooling. An in-house Matlab ${ }^{\mathrm{TM}}$ code, capable of automatically generating mutually constrained truss and membrane meshes of arbitrary perimeter shape, has been used to generate the mesh for the blank, in this case using 63,078 truss (diameter $=0.02 \mathrm{~mm}$, modulus $\left.=30 \times 10^{6} \mathrm{~Pa}\right)$ and 31,168 square membrane (thickness $0.7 \mathrm{~mm}$ ) elements of side length $2 \mathrm{~mm}$ (similar to the mesh density used in [2]). The material density of all deformable elements was $4905 \mathrm{kgm}^{-3}$. Use of an artificially low modulus and high density decreased simulation times (approximately 2 hours using a 32 bit Windows OS with Intel Core i7-2720QM CPU @ 2.2 GHz and 4 GB RAM, future investigations will examine the sensitivity of shear angle predictions to these modifications). The Stress Power Model is formulated in the fibre-bisector system and is implemented here in membrane elements using the VUMAT user-subroutine facility of the commercial finite element code Abaqus Explicit ${ }^{\mathrm{TM}}$ [2]; it employs the reference frame transformations and fibre-tracking system originally implemented in the original non-orthogonal constitutive model implemented by Yu et al. [26]. The model uses tabulated elastic input curves selected during the simulation according to the shear rate within a given element. In so doing, rate-dependent shear behaviour at any given temperature (here $200^{\circ} \mathrm{C}$ ) can be simulated by incorporating input predictions from the 'scaled' multi-scale energy model described in Section 4.3. Non-linear spring elements with properties given in Table 2 were used to attach the blank to the blank-holder frame. The latter was simulated using rigid body elements. Tabs on the blank were simulated as fibre-reinforced unmolten PP with a matrix modulus of $0.2 \mathrm{GPa}$ and a yield stress of $400 \mathrm{kPa}$. Inertial effects were negligible in all simulations. An image of the initial numerical set-up is shown in Figure 13. The full blank, rather than a quarter of the blank plus symmetry boundary conditions has been employed as future work will involve sensitivity studies involving variability of boundary conditions and initial fibre angles in the 
blank. In order to match experiments as closely as possible the simulation was run in several steps: (i) Each straight section of the blank holder frame shown in Figure 13 was first moved outwards away from the blank by a distance of $10 \mathrm{~mm}$ in order to induce a preliminary tension in the blank. In experiments, the springs had to be stretched slightly, from frame to blank, in order to attach them to the sheet (see Video 1a) (ii) Gravity was applied with acceleration set at a reduced value of $2.5 \mathrm{~ms}^{-2}$. This caused the sheet to start accelerating downwards during this and the next step (iii) The punch was moved downwards. During this forming step, due to gravitational acceleration the bottom of the blank eventually touched the top surface of the female tool at about 80 percent of full closure of the male punch tool. This meant that the underside of the blank was dragged across the upper surface of the female tool during the final stage of the forming process, imparting friction, and effectively adding to the in-plane tension in the forming sheet. This additional friction allowed the simulation to run to completion without errors. Video $1 \mathrm{~b}$ shows how the falling blank eventually touches the upper surface of the female tool in the simulation. Video 1c shows an experiment using a specially designed female tool with the lower body of the tool cut-away. This experiment permitted observations of the forming process from below and shows how, in reality, the molten forming thermoplastic composite sheet is also in contact with the surface of the room-temperature female tool when drawn into the cavity during the forming process, due to the sagging of the sheet under its own weight.

Two simulations are shown from this investigation in Figure 14; each uses a very different value of the constant coefficient of friction between tools and blank, i.e. 5.0 and 0.3. Previous studies have found steady state friction values between molten sheet and high temperature tooling for glass/PP composite to range from 0.05 (at high temperature, low sliding speed \& high pressure) to 0.5 (at low temperature, high sliding speed \& low pressure) and much higher static peak friction values at around twice the steady state values are not uncommon [14]. Even higher friction values might be anticipated when the hot thermoplastic sheet contacts cold tooling as the size of the effective friction coefficient depends strongly on temperature, pressure and sliding speed. In the simulations of this investigation, the model is rate but not temperature dependent and only a constant friction value can be assigned, consequently neither the rapid cooling of the sheet nor the changing contact condition with the tooling can, as yet, be modelled. As such, the first simulation uses a friction coefficient that is set to be artificially high value at 5.0 and is 
designed to account for the rapid cooling, freezing and reduction in mobility of the thermoplastic matrix composite when contacting the room temperature tooling, albeit in a very rudimentary way. The second simulation uses a more realistic value of 0.3 but in no way accounts for the cooling of the sheet and is therefore probably less constrained than in reality. (Note that due to the values used for the acceleration due to gravity and the density of the blank, the normal force due to the weight of the blank is reduced by a factor of about 1.5 and so friction caused by the weight of the sheet acting downwards on the female tool should be adjusted accordingly, to effective values of about 3.3 and 0.2 ).

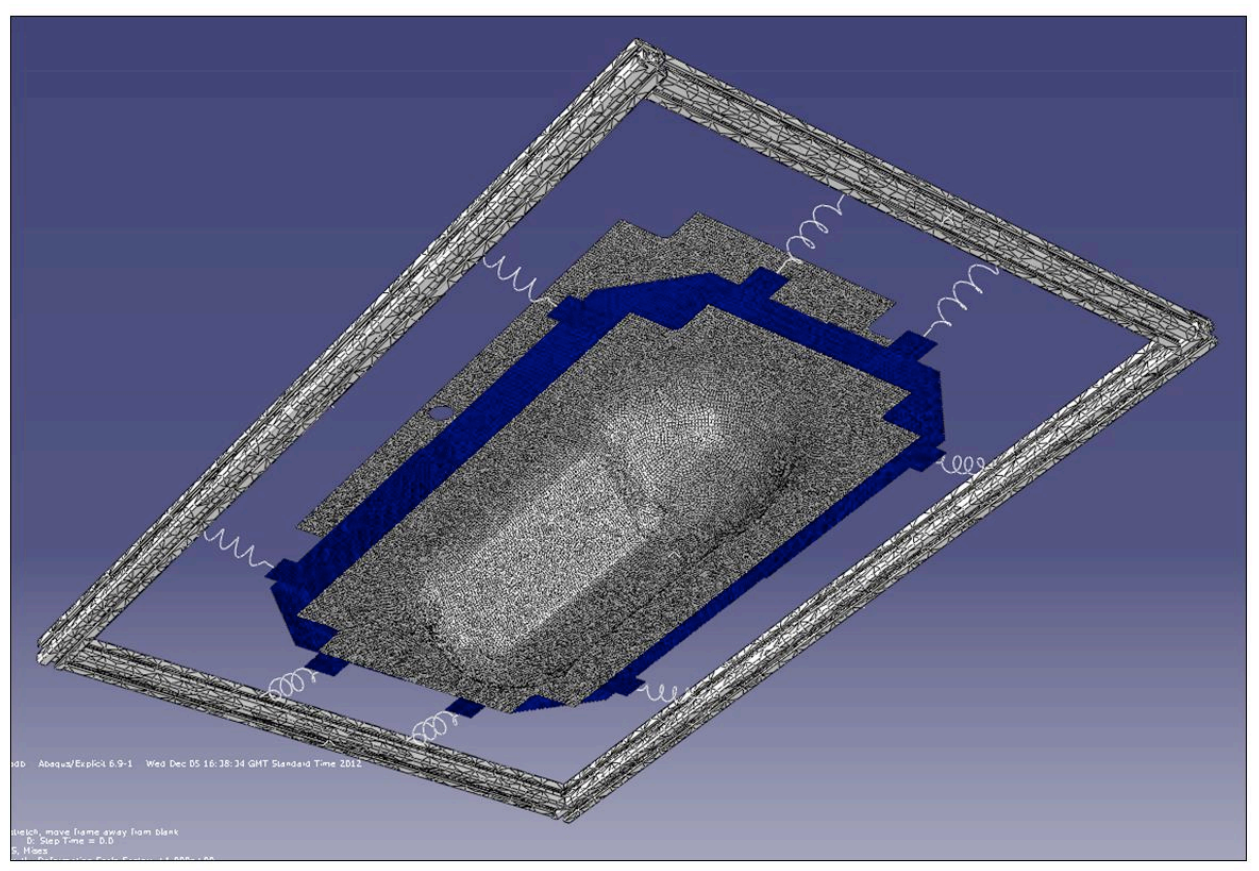

Figure 13. Numerical set-up used in simulations showing the relative positions of the punch, die and blank. The springs are attached in approximate positions to the supporting frame to apply tension to the forming sheet. 

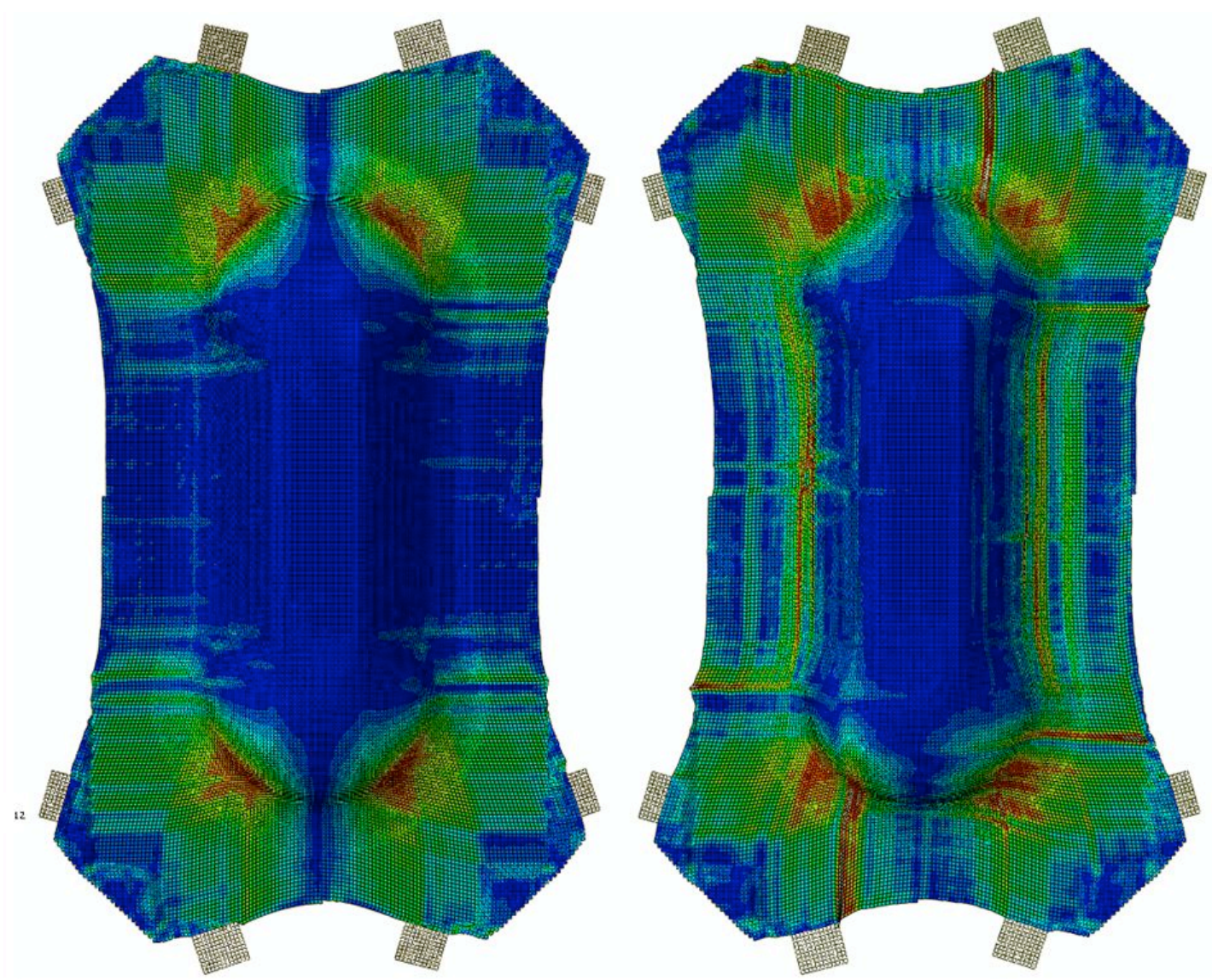

Figure 14. Forming prediction at full tool closure. (a) Using a friction coefficient of 5.0 and (b) Using a friction coefficient of 0.3 . The colour legend indicates the shear angle. A maximum angle of $42.4^{\circ}$ has been used in the colour scale to facilitate comparison with results in [7]. 

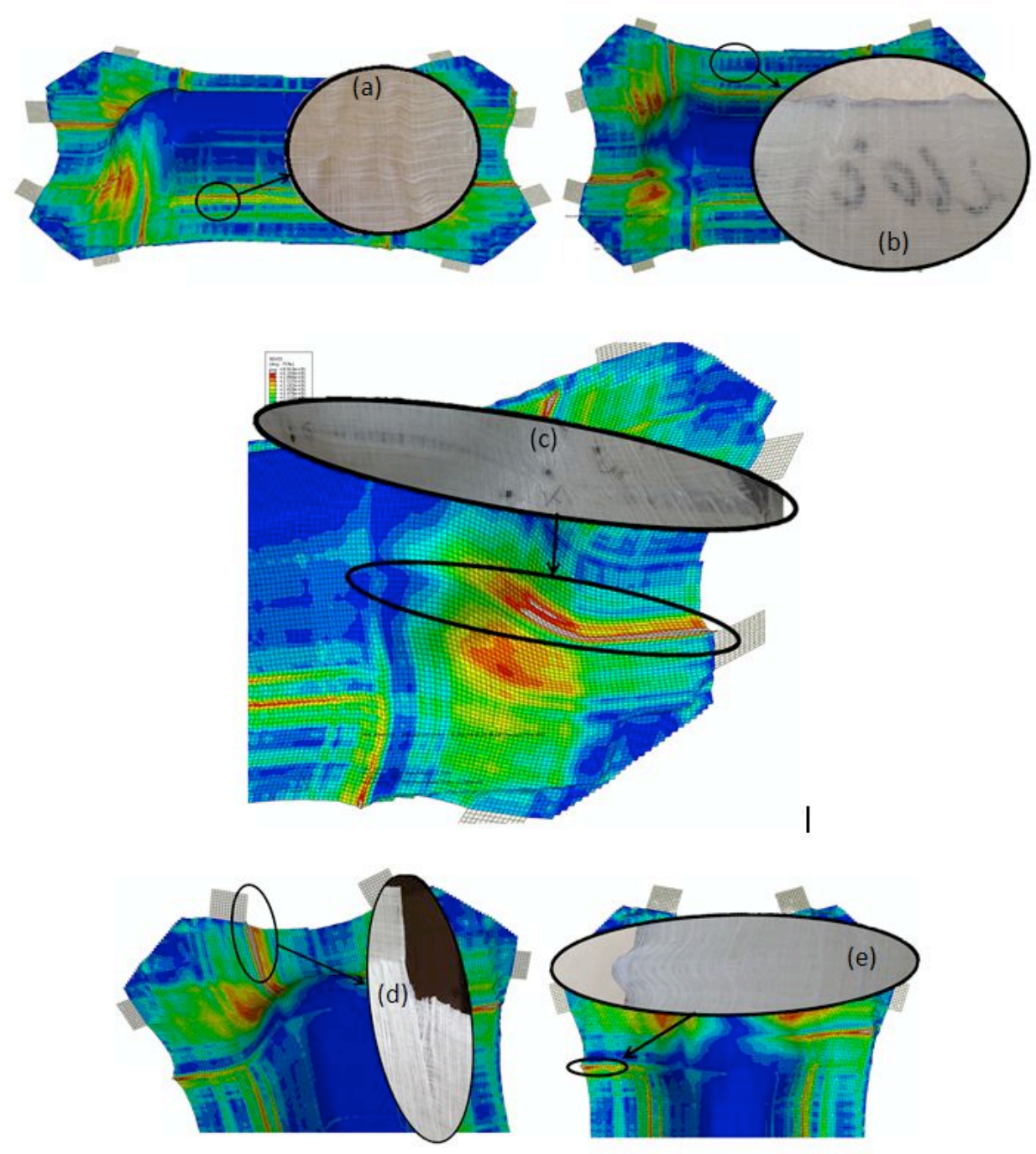

Figure 15. Location of actual defects on formed parts. (a) In-plane buckling along fibre direction with a wavelength of about $2 \mathrm{~mm}$, a line of localised shear appears in the simulation along the length of the part passing through this region. (b) In-plane buckling extending to edge of sheet, localised shear regions extending to perimeter are also seen in simulations though usually occur closer to corners. (c) Localised line of high shear or in extreme cases, slip (seen here) extending from tabs into the main body of the formed part. (d) Ply splitting next to tabs initiating the defect seen in (c). (e) In-plane buckling extending to edge of sheet, this time in same location as that predicted in simulation. 

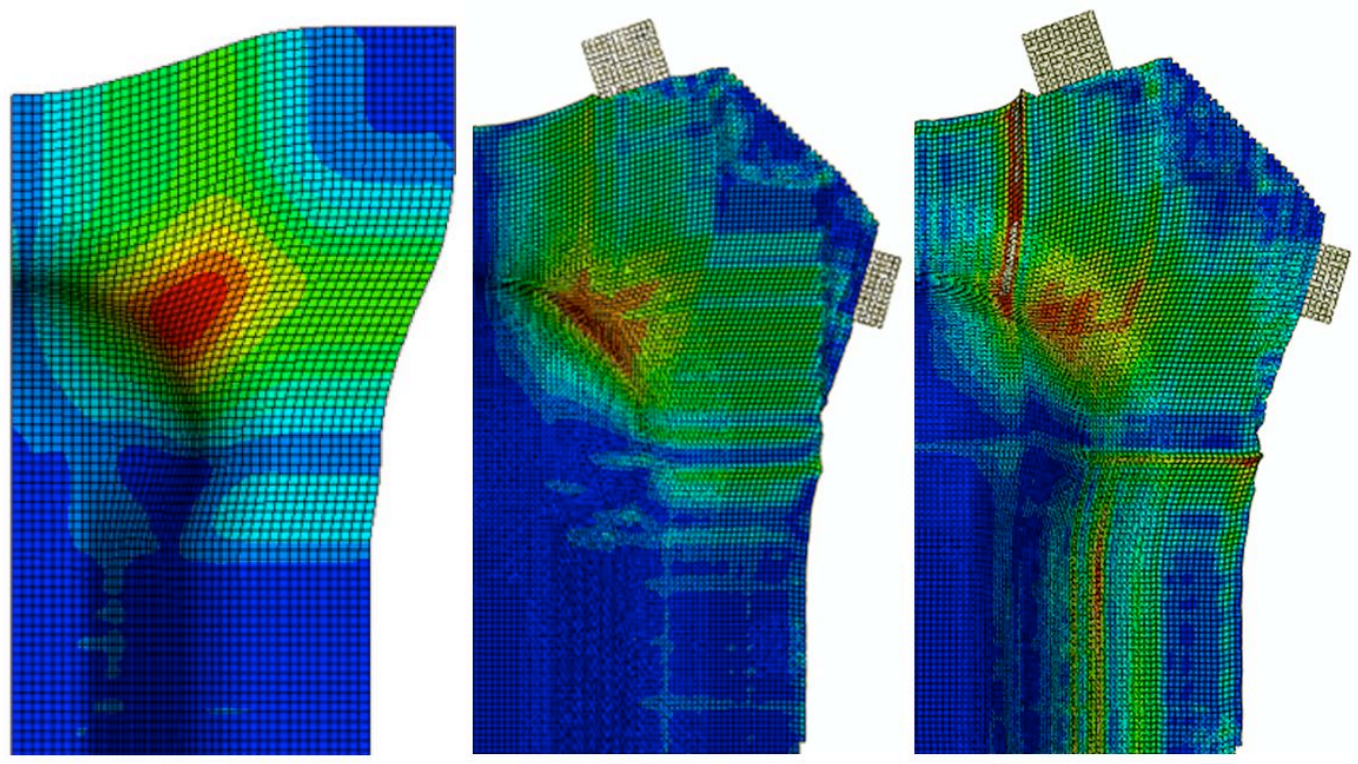

Figure 16. Full field numerical shear angle predictions from: (a) from Khan et al [7] and (b) from this investiation with friction $=5.0$ (c) from this investiation with friction $=0.3$. The colour legend indicates the shear angle and maximum angle of $42.4^{\circ}$ on the scale has been used in all diagrams to facilitate comparison with results in [7].
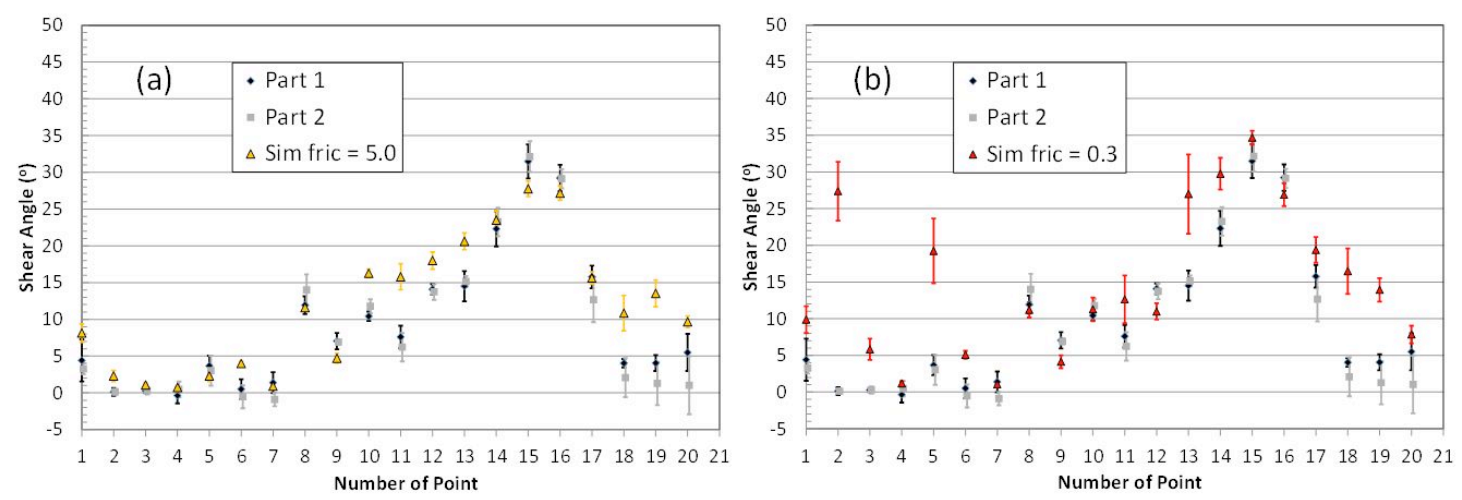

Figure 17. Data from Figure 11a are re-plotted together with results of the simulations. Again error bars represent the standard deviation (top to bottom). (a) Simulation results (triangles with yellow fill) produced using a friction coefficient of 5.0 and (b) Simulation results (triangles with red fill) produced using a friction coefficient of 0.3 .

The shear angle predictions from the simulation at full closure of the tooling are given in Figure 14. The two simulations show differences between each other and also between their own quadrants. The latter effect is presumably due to the approximate positioning of the attachment of the springs to the support frame, which had a tolerance of a few $\mathrm{mm}$ in their positioning. The most notable difference between the 
two simulations is the occurrence of patchy and localized shear zones in the low friction simulation, in some instances these extended to the perimeter of the formed sheet. After running numerous simulations it was found that: (i) The localized shear zones were suppressed by a high coefficient of friction and (ii) For low friction conditions, the severity of the localized shear zones increased with decreasing temperature or increasing rate, suggesting that a higher material stiffness promoted shear localization. These localized shear zones were found to correspond quite well to defects seen in the actual formed parts. Figure 15 shows the location and nature of these defects on the formed parts in relation to the positions of the localized shear zones in the simulation. Observations suggest that while the use of springs to tension the blank is a good practical solution for thermoforming advanced composites, it can nevertheless result in defects. Perhaps surprisingly, simulations can be used to predict these defects, though to do so accurately, requires more precise modeling of both the material and friction behavior. If this could be achieved then numerical optimization of process parameters including temperature, friction and the position, stiffness and number of springs, could be used to eliminate defects.

A full-field comparison with the numerical prediction of [7] is also shown in Figure 16 and is aimed to provide a qualitative but comprehensive method of quickly assessing the influence that material and boundary conditions can make on forming behaviour. The mechanical simulation from [7] was produced with their own user-defined hypo-elastic constitutive model implemented in VUMAT, though here the fibre stiffness was incorporated in the membrane elements and the constitutive model employed for those simulations was rate independent, matching the behaviour of the fabric material used in their experiments. The full holder condition, as might be expected, produces a less patchy result.

Quantitative predictions of the current investigation were calculated in each quadrant by averaging the shear angle at the node closest to the measurement point (1 to 20) with those of its nearest neighbours, and then taking the average for each position across all four quadrants. Results are shown in Figure 17. For the simulation with a coefficient of friction $=5.0$, the predictions in Figure $17 \mathrm{a}$ are reasonably close at 9 of the 20 measurement positions. Shear angles are over predicted at points 10-13 and under-predicted at points 15 and 16 . For the simulation with a coefficient of friction $=0.3$, the predictions in Figure $17 \mathrm{~b}$ are reasonably close at 7 of the 20 measurement positions. The high shear region is more closely predicted 
than for the high friction simulation at points 15 and 16. Points 2, 5 and 13 correspond to the locations of localized shear zones and therefore have large error bars and are a long way from experimental results. These simulations show that tool/ply friction is an important factor and suggest that accurate modelling of both friction and material behaviour is essential if precise numerical predictions are to be made for high temperature thermoforming of thermoplastic matrix cross-ply laminates. A more comprehensive numerical investigation of all the cases presented in this paper along with a sensitivity study into the effects of rate, temperature and friction on the composite's thermoforming behavior is planned for the future.

\section{Conclusions}

An experimental investigation into the thermoforming of a biaxial thermoplastic glass/PP cross-ply advanced composite has been conducted. At high temperatures, the meso-scale kinematics of the sheet are heterogeneous, as has been observed previously for other types of advanced composites and engineering fabrics. As the temperature drops, the shear profile across the sheet changes and the composite shears more like a homogeneous continuum. Thermoforming results show that inter-ply slip is negligible and the dominant mode of deformation is trellis shear. Consequently, biaxial constitutive models are thought to be appropriate tools for simulating their thermoforming behavior. An alternative boundary condition, using springs rather than a friction-based blank holder, has been employed and found to have several practical advantages when conducting thermoforming experiments; the method is flexible, easy to use and naturally facilitates heating of the entire blank prior to forming. However, this concentrated application of tension can lead to defects such as in-plane micro-buckling and localized zones of high shear. The change in both the material and the boundary conditions results in a significantly different shear angle distribution across the formed sheet when compared to previous investigations using the double-dome benchmark geometry with a full blank-holder and glass fabric. Preliminary numerical simulations demonstrate it is possible to model this alternative experimental set-up and encouraging initial results have been produced both in terms of full field shear angle predictions and also of localized defects. However, it is clear that simulation of the thermoforming of advanced thermoplastic composites must take full account, not just of the rate and temperature dependent material behavior but also of the complex tool/ply friction interaction if accurate predictions are to be made. Eventually, the effects of non-uniform 
initial temperature distribution and cooling of the blank both due to removal from the oven and also due to contact with the tooling can be included in simulations to improve accuracy.

\section{ACKNOWLEDGEMENTS}

The authors wish to thanks the Royal Academy of Engineering for the Global Research Award used to support this work and also the Portuguese Agency for Innovation (Agencia de Inovação - AdI) for funds provided through the projects Tooling Edge and New Generation Hybrid Fuel Tank.

\section{APPENDIX A: Tabulated shear angle measurements for Cases 1 to 5}

\begin{tabular}{|c|c|c|c|c|c|c|}
\hline & & & \multicolumn{2}{|l|}{ CASE 1} & \multicolumn{2}{|l|}{ CASE 2} \\
\hline \multicolumn{3}{|c|}{ Coordinates (mm) } & Shear & \begin{tabular}{|l|l|} 
Standard \\
\end{tabular} & Shear & Standard \\
\hline Point & 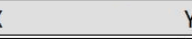 & & angle (deg) & deviation $/ 2$ (deg) & angle (deg) & deviation $/ 2$ (deg) \\
\hline 1 & 85 & 65 & 4.4 & 2.9 & 3.3 & 0.8 \\
\hline 2 & 60 & 40 & 0.1 & 0.5 & 0.1 & 0.4 \\
\hline 3 & 45 & 40 & 0.3 & 0.3 & 0.3 & 0.5 \\
\hline 4 & 10 & 40 & -0.4 & 1.1 & 0.5 & 1.1 \\
\hline 5 & 60 & 80 & 3.7 & 1.4 & 3.0 & 2.0 \\
\hline 6 & 45 & 80 & 0.5 & 1.3 & -0.5 & 1.6 \\
\hline 7 & 10 & 80 & 1.4 & 1.4 & -0.9 & 0.9 \\
\hline 8 & 25 & 120 & 11.9 & 1.2 & 14.0 & 2.1 \\
\hline 9 & 5 & 140 & 7.0 & 1.1 & 6.9 & 0.4 \\
\hline 10 & 15 & 160 & 10.4 & 0.6 & 11.8 & 0.9 \\
\hline 11 & 17.3 & 202.7 & 7.6 & 1.5 & 6.2 & 1.9 \\
\hline 12 & 26.0 & 188.0 & 14.1 & 0.7 & 13.7 & 1.1 \\
\hline 13 & 34.7 & 171.8 & 14.5 & 2.1 & 15.2 & 0.7 \\
\hline 14 & 44.6 & 155.9 & 22.3 & 2.4 & 23.3 & 1.9 \\
\hline 15 & 52.0 & 142.1 & 31.5 & 2.3 & 32.1 & 2.1 \\
\hline 16 & 60.0 & 127.6 & 29.2 & 1.8 & 29.1 & 1.3 \\
\hline 17 & 68.9 & 112.6 & 15.8 & 1.5 & 12.7 & 3.0 \\
\hline 18 & 77.1 & 97.2 & 4.0 & 0.6 & 2.1 & 2.7 \\
\hline 19 & 84.9 & 83.4 & 4.1 & 1.1 & 1.3 & 2.9 \\
\hline 20 & 94.4 & 67.4 & 5.5 & 2.5 & 1.0 & 3.9 \\
\hline
\end{tabular}

Table A1. Cases 1 and 2, the average shear angle and standard deviation at each of the measurements points, 1-20 is given along with (standard deviation)/2 which was used to plot the error bars in Figure 11. 


\begin{tabular}{|c|c|c|c|c|c|c|}
\hline & & & \multicolumn{2}{|l|}{ CASE 3} & \multicolumn{2}{|l|}{ CASE 4} \\
\hline \multicolumn{3}{|c|}{ Coordinates $(\mathrm{mm})$} & \multirow{2}{*}{$\begin{array}{l}\text { Shear } \\
\text { angle (deg) }\end{array}$} & \multirow{2}{*}{$\begin{array}{l}\text { Standard } \\
\text { deviation/2 (deg) }\end{array}$} & \multirow{2}{*}{$\begin{array}{l}\text { Shear } \\
\text { angle (deg) }\end{array}$} & \multirow{2}{*}{$\begin{array}{l}\text { Standard } \\
\text { deviation/2 (deg) }\end{array}$} \\
\hline Point & $x$ & $\mathrm{Y}$ & & & & \\
\hline 1 & 85 & 65 & 14.2 & 0.7 & 13.1 & 3.5 \\
\hline 2 & 60 & 40 & 0.9 & 1.2 & 7.7 & 0.9 \\
\hline 3 & 45 & 40 & 14.4 & 2.9 & 14.6 & 3.1 \\
\hline 4 & 10 & 40 & 12.9 & 1.1 & 18.8 & 1.4 \\
\hline 5 & 60 & 80 & 10.2 & 3.3 & 5.1 & 1.6 \\
\hline 6 & 45 & 80 & 0.4 & 1.6 & 3.5 & 1.7 \\
\hline 7 & 10 & 80 & 13.7 & 1.3 & 18.1 & 1.9 \\
\hline 8 & 25 & 120 & 8.6 & 0.6 & 14.4 & 0.6 \\
\hline 9 & 5 & 140 & 24.7 & 3.2 & 29.1 & 1.0 \\
\hline 10 & 15 & 160 & 38.0 & 1.3 & 39.1 & 2.3 \\
\hline 11 & 0.0 & 161.5 & 42.9 & 2.4 & 45.8 & 2.1 \\
\hline 12 & 23.1 & 160.9 & 30.7 & 2.1 & 25.4 & 5.4 \\
\hline 13 & 40.6 & 160.9 & 8.2 & 1.4 & 11.9 & 1.9 \\
\hline 14 & 52.7 & 160.9 & 3.3 & 2.1 & 4.5 & 2.5 \\
\hline 15 & 52.3 & 134.0 & 0.2 & 1.4 & 2.8 & 1.5 \\
\hline 16 & 52.7 & 100.8 & 8.3 & 3.1 & 5.7 & 2.3 \\
\hline 17 & 52.3 & 64.9 & 6.1 & 2.2 & 2.6 & 1.3 \\
\hline 18 & 73.5 & 64.2 & 20.2 & 1.1 & 16.0 & 1.3 \\
\hline 19 & 92.9 & 64.6 & 10.9 & 1.2 & 7.9 & 2.7 \\
\hline 20 & 111.0 & 64.6 & & & & \\
\hline
\end{tabular}

Table A2. Cases 3 and 4, the average shear angle and standard deviation at each of the measurements points, 1-20 is given along with (standard deviation)/2 which was used to plot the error bars in Figure 11.

\begin{tabular}{|c|c|c|c|c|c|c|}
\hline & & & \multicolumn{2}{|l|}{ CASE $5(A \& C)$} & \multicolumn{2}{|l|}{ CASE 5 (B \& D) } \\
\hline \multicolumn{3}{|c|}{ Coordinates $(\mathrm{mm})$} & \multirow{2}{*}{$\begin{array}{l}\text { Shear } \\
\text { angle (deg) }\end{array}$} & \multirow{2}{*}{$\begin{array}{l}\text { Standard } \\
\text { deviation/2 (deg) }\end{array}$} & \multirow{2}{*}{$\begin{array}{l}\text { Shear } \\
\text { angle (deg) }\end{array}$} & \multirow{2}{*}{$\begin{array}{l}\text { Standard } \\
\text { deviation/2 (deg) }\end{array}$} \\
\hline Point & $x$ & $Y$ & & & & \\
\hline 1 & 85 & 65 & -3.6 & 1.2 & -12.5 & 2.5 \\
\hline 2 & 60 & 40 & -5.7 & 1.1 & 14.9 & 2.7 \\
\hline 3 & 45 & 40 & 8.0 & 1.9 & 10.2 & 3.7 \\
\hline 4 & 10 & 40 & 15.2 & 0.8 & 10.0 & 0.2 \\
\hline 5 & 60 & 80 & -7.5 & 2.8 & -11.4 & 0.5 \\
\hline 6 & 45 & 80 & -5.3 & 1.1 & 2.3 & 0.8 \\
\hline 7 & 10 & 80 & 13.5 & 0.8 & 8.9 & 0.4 \\
\hline 8 & 25 & 120 & 10.7 & 1.4 & 9.2 & 1.4 \\
\hline 9 & 5 & 140 & 26.2 & 2.9 & 25.0 & 1.3 \\
\hline 10 & 15 & 160 & 40.6 & 0.9 & 28.5 & 1.3 \\
\hline 11 & 0.0 & 161.5 & 35.1 & & 34.1 & \\
\hline 12 & 23.1 & 160.9 & 34.8 & 2.4 & 26.1 & 0.6 \\
\hline 13 & 40.6 & 160.9 & 10.6 & 0.9 & 10.6 & 1.9 \\
\hline 14 & 52.7 & 160.9 & 5.0 & 0.3 & 2.3 & 0.1 \\
\hline 15 & 52.3 & 134.0 & 2.1 & 0.9 & -11.0 & 3.4 \\
\hline 16 & 52.7 & 100.8 & -10.0 & 0.8 & -13.5 & 3.0 \\
\hline 17 & 52.3 & 64.9 & 7.8 & 0.0 & -4.1 & 1.7 \\
\hline 18 & 73.5 & 64.2 & 15.2 & 0.2 & 13.1 & 2.2 \\
\hline 19 & 92.9 & 64.6 & 1.1 & 1.0 & 15.9 & 0.2 \\
\hline 20 & 111.0 & 64.6 & & & & \\
\hline
\end{tabular}

Table A3. Case 5, the average shear angle and standard deviation at each of the measurements points, 1-

20 is given along with (standard deviation)/2 which was used to plot the error bars in Figure 11 


\section{REFERENCES}

[1] Bel, S., Hamila, N., Boisse, P. and Dumont, F. Finite element model for NCF composite reinforcement preforming: Importance of inter-ply sliding, Composites: Part A, 43, 2269-2277, 2012

[2] Harrison, P., Yu, W.R. and Long, A.C. Rate Dependent Modelling of the Forming of Viscous Textile Composites, Composites: Part A, 42, pp. 1719-1726, 2011

[3] Sharma, S.B. and Sutcliffe, M.P.F. A simplified finite element model for draping of woven material, Composites: Part A, 35, 637-643, 2004

[4] Cherouat, A. and Billoët J.L. Mechanical and numerical modelling of composite manufacturing processes deep-drawing and laying-up of thin pre-impregnated woven fabrics. Journal of Materials Processing Technology, 118, 1-3, 3, 460-471, 2001

[5] http://www.wovencomposites.org/index.php Woven Composites Benchmark Forum, 2008 (accessed $7^{\text {th }}$ Dec 2012)

[6] Willems, A., Forming simulation of textile reinforced composite shell structures, $\mathrm{PhD}$ thesis, Katholieke Universiteit Leuven, 325, 2008

[7] Khan, M.A., Mabrouki, T., Vidal-Sallé, E. and Boisse, P. Numerical and experimental analyses of woven composite reinforcement forming using a hypoelastic behaviour. Application to the double dome benchmark. Journal of Materials Processing Technology, 210, pp. 378-388, 2010

[8] Khan, M. A., Boisse P. and Mabrouki, T. Numerical and experimental forming analysis of woven composites with double dome benchmark, International Journal of Material Forming, 2, 1, 201204, 2009

[9] Peng, X. and Rehman, Z.U. Textile composite double dome stamping simulation using a nonorthogonal constitutive model, Composites Science and Technology, 71, pp. 1075-1081, 2011

[10] Willems, A., Lomov, S.V., Verpoest, I., Vandepitte, D., Harrison, P. and Yu, W.R. Forming simulation of a thermoplastic commingled woven textile on a double dome. International Journal of Material Forming, 1, 965-968, 2008

[11] Willems, A. Lomov, S.V. Vandepitte, D. Verpoest. I., Double dome forming simulation of woven textile composites, $11^{\text {th }}$ ESAFORM Conference on Material Forming, Glasgow, UK, 26-28 April, 747-750, 2006 
[12] Lee, W., Um, M.-K., Byun, J.H., Boisse, P. and Cao, J. Numerical study on thermo-stamping of woven fabric composites based on double-dome stretch forming, International Journal of Material Forming, 3(2), S1217-S1227, 2010

[13] http://www.polystrand.com

[14] Harrison, P., ten Thije, R., Akkerman, R. and Long, A.C. Characterisation and modelling friction at the tool-ply interface for thermoplastic woven composites, World Journal of Engineering, 7.1, 5-22, 2010

[15] ten Thije, R.H.W., Akkerman, R., Ubbink, M. and van der Meer, L. A lubrication approach to friction in thermoplastic composites forming processes, Composites Part A, 42, 8, 950-960, 2011

[16] Launay, J. Hivet, G. Duong, A.V. and Boisse P., Experimental analysis of the influence of tensions on in plane shear behaviour of woven composite reinforcements, Composites Science and Technology, 68, 506-515, 2008

[17] Milani, A.S., Nemes, J.A., Lebrun, G. and Bureau M.N. A Comparative Analysis of a Modified Picture Frame Test for Characterization of Woven Fabrics, Polymer Composites, 561-568, 2010

[18] Harrison, P., Clifford, M.J., Long, A.C. and Rudd, C.D. A constituent-based predictive approach to modelling the rheology of viscous textile composites, Composites: Part A, 38, 7-8, 915-931, 2004

[19] Potluri, P., Perez Ciurezu, D.A. and Ramgulam, R.B. Measurement of meso-scale shear deformations for modelling textile composites, Composites Part A, 37, 2, 303-314, 2006

[20] Potter, K., Bias extension measurements on cross-plied unidirectional prepreg Composites Part A, $33,63-73,2002$

[21] Harrison, P., Wiggers, J., Long, A.C. and Rudd, C.D. A constitutive model based on meso and micro kinematics for woven and stitched dry fabrics, Proceedings of $14^{\text {th }}$ International Conference on Composite Materials, 14-18 ${ }^{\text {th }}$ July, San Diego, California, USA, 2003

[22] Wang, J. Predictive modelling and experimental measurement of composite forming behavior, $\mathrm{PhD}$ thesis, University of Nottingham, (2008)

[23] Boisse, P., Meso-macro approach for composites forming simulation, J Mater Sci, 41, 6591-6598, 2006 
[24] Harrison, P., Clifford, M.J., Long, A.C. and Rudd, C.D. Constitutive modelling of impregnated continuous fibre reinforced composites: a micro-mechanical approach, Plastics, Rubber and Composites, 2, 31, 76-86, 2002

[25] http://rsbweb.nih.gov/ij/ (accessed 5th April 2012)

[26] Yu, W.R., Pourboghrat, F., Chung, K., Zampaloni, M. Kang, T.J., Non-orthogonal constitutive equation for woven fabric reinforced thermoplastic composites, Composites: Part A, 33 1095-1105, 2002 